YАK 354

ББК 66.3(0),123

DOI 10.22394/1682-2358-2017-3-46-53

T.M. Tatubaev, degree seeking applicant of the Political Science and International Relations Department, Chelyabinsk State University, Chairman of the National Anti-Corruption Bureau of the Republic of Kazakbstan Agency for Civil Service Affairs and Corruption Control

\section{SOCIAL CONDITIONS CONDUCIVE \\ TO OFFENCES \\ WITH ABUSE \\ OF OFFICIAL POSITION \\ BY GOVERNMENT \\ OFFICIALS \\ OF THE REPUBLIC \\ OF KAZAKHSTAN}

Factors to contribute to corrupt motives in the conduct of public servants of the Republic of Kazakhstan are analyzed. Measures to neutralize them, including the positional remuneration scheme at civil service, overcoming conservative attitudes, creating the atmosphere of inevitability of punishment for an offence committed for mercenary motives, are proposed.

Key words and word-combinations. corruption, public servants, anticorruption policy.
T.M. Татубаев, соискатель кафедрь политических наук и международньгх отношений Челябинского государственного университета, председатель Начионального бюоро по противодействию коррупиии Агентства Республики Казахстан по делам государственной службы и противодействию коррупщии (email: kafedrapolit@ mail.ru)

\section{СОЦИААЬНЫЕ УСАОВИЯ, СПОСОБСТВУЮЩИЕ ПРАВОНАРУШЕНИЯМ С ИСПОАЬЗОВАНИЕМ САУЖЕБНОГО ПОАОЖКЕНИЯ ГОСУААРСТВЕННЫМИ САУЖКАЩИМИ РЕСПУБАИКИ КАЗАХСТАН}

Аннотация. Проанализированы факторы, обусловливающие коррупционные мотивы в поведении государственных служащих Республики Казахстан. Предложены меры по их нейтрализации, среди которых переход на позиционную систему оплаты труда на госслужбе, преодоление консервативных социальных установок, создание атмосферы неотвратимости наказания за должностное преступление, совершенное по корыстным побуждениям.

Ключевые слова и словосочетания: коррупция, государственные служащие, антикоррупционная политика.

K оррупция - непременный спутник соџиальной истории. Впервые она заявица о себе на этапе генезиса раннегосударственных форм человеческого общежития, когАа 
функции управления начали обособцяться. С этого же времени появляются особые - персональные и групповые - интересы миц, осушествлявших Аанные функции. Коррупционные отношения непрерывно эволющионировали, реагируя на формаџионные савиги, изменение типов государственного устройства, трансформацию политических режимов. В современном Казахстане коррупция превратилась в устойчивый соџиальный институт, элемент вертикали власти, который коррелирует с политическими, экономическими, культурными векторами развития страны. Это значит, что курс на улучшение «внутреннего киимата» может способствовать снижению показателей

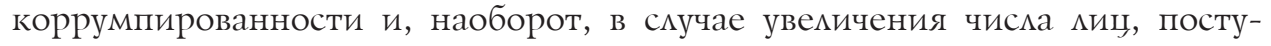
пающих на государственную службу исключительно ради удовлетворения корыстных побуждений, произойдет консервация и даже обострение имеющихся проблем.

Усмовия, порождающие коррупџию, многообразны. Среди них есть универсальные, которые свойственны практически всем государствам, особенные - те, что складываются в транзитивные или кризисные периоды, и специфические, характеризующие конкретное общество. Первые являются непреднамеренным результатом действий правительства по введению экспортно-импортных ограничений, выдаче мицензионно-разрешительных документов, предоставлению субсидий и налоговых мьгот предприятиям, отраслям или регионам, осуществлению контромя над ценами, курсами ценных бумаг и т.А. Очевидно, что чем обширнее перечень разрешений, которые необходимо получить Аля мегального ведения бизнеса, тем выше степень госуАарственного регулирования экономики и больше благовидных предлогов Амя административного вмешательства в деловые отношения. Центральные органы, не имея возможности напрямую контактировать с каждым заинтересованным актором, вынужжены делегировать соответствующие полномочия чиновникам-агентам, самостоятельно решающим, быть им честными или нет.

В Казахстане (131-е место по рейтингу восприятия коррупџии Трансперенси Интернешни - IPC TI в 2016 г.) миџензированию со стороны респубмиканских министерств и ведомств подмежат 26 сфер деятельности, включая такие, как образование и культура [1]. Это по европейским меркам очень много, хотя за последние несколько мет были упразднены семь миџензий и 175 разрешений. Аля сравнения, в Аании (1-е место IPC TI в 2016 г.) ограничения и дополнительные требования касаются только четырех видов занятий: продажи алкоголя; торговли продуктами питания; пассажирских и грузовых перевозок; фармацевтических и медицинских услуг. Ведают этим исключительно местные власти - муниципалитеты, отделы полиции, управмения зАравоохранения [2]. В Казахстане же санитарные правика и нормы, например Аля пунктов общественного питания - ресторанов, столовых, кафе, содержат 230 обязательных условий, от вентиляџии до мытья посуды. Намичествует даже требование к температуре в курительной комнате. Всего в Республике действует 41 свод требований СанПиН, где содержится свыше восьми тысяч разАичных позиций.

ОАнако подавляющая часть казахстанцев считает оправданной ведущую 
роль государства в хозяйственной жизни, поскольку частный сектор пока не способен предложить удовцетворительное решение пробцемы соџиацьной ответственности. Тем не менее 11,6\% индивидуальных предпринимателей и

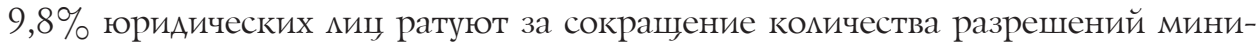
мум наполовину путем введения уведомительного порядка и саморегулирования $[3$, с. 114].

Аиберальные рыночные реформы 1990-х годов знаменовали собой начамо переходного периода. Он сопровождался кардинальной момкой прежней идеологии, нравственных ценностей, привычного жкизненного уклада. Преобразования опережали институциональные изменения, вследствие чего образовывались многочисленные правовые макуны. Разбирательства «по понятиям» и «откаты» стали непременным атрибутом как самого процесса приватизаџии, так и скмадывающейся новой системы общественных отношений, что не могмо не наложить отпечатка на последующее развитие. В этом заключается особенность казахстанского «демократического транзита», породившего весьма своеобразную кризисную модель коррупции.

Разгосударствление собственности происходияо в стране, где народное хозяйство имело ярко выраженную сырьевую ориентацию с высокой конџентрацией добывающих производств и централизованным отраслевым принципом управления ими. Ао 60\% товаров народного потребления завозилось извне. Разрушение кооперационных цепочек, вызванное распадом СССР, повлекло полную или частичную остановку более полутора тысяч предприятий. Резко увеличился уровень безработицы, а гиперинфмяция обесценила накопленные ранее сбережкения.

Все это осложнило участие трудящихся в третьем (Аенежном) этапе приватизаџии в 1996-1998 гг. Тогда в частные руки были переданы целые секторы в электроэнергетическом, нефтегазовом, нефтехимическом, метациургическом, горнорудном и Аругих ресурсодобывающих производственных комплексах стратегического значения. Самые «макомые куски» государственной собственности достались представителям бывшей партийно-советской номенклатуры. Они сохранили исходный капитал в виде мичных связей, опробованных рычагов влияния, учрежденных коммерческих компаний и валютных финансовых активов. Кроме того, некоторые сумели не только удержать свои позиџии в бюрократической иерархии, но и существенно укрепить их, заложив порочную традицию сращивания власти и бизнеса, когда грань между частными и государственными интересами становится практически неосязаемой.

Немалая часть фиагманов казахстанской индустрии оказалась в распоряжении инвесторов-нерезидентов, и их мощности были переориентированы на дальнее зарубежье. В 2008 г. генеральный директор медиахоцдинга «Эксперт РА Казахстан» В. Фадеев заметил: именно предприятия, принадлежкащие иностранным собственникам, такие как АO «Казцинк», АО «АрселорМиттам», консорџиум «Карачаганак Петролиум Оперейтинг», отличаются максимахьной «закрытостью» своей отчетности [4] .

По данным Global Financial Integrity - американской исследовательской организации, анацизирующей незаконные финансовые потоки из развиваю- 
щихся стран, из Казахстана в период с 2004 по 2013 г. было вывезено около 167,4 млрА Аомларов. Важнейшим каналом GFI называет операции занижения / завышения фактической стоимости экспорта или импорта при таможенном декларировании - на них приходится 83,4\% нелегального оттока Аенег [5]. Высокие объемы «теневых» операций свидетемьствуют о наличии неформальных центров власти - организованной преступности, вступившей в сговор с коррупционерами.

Объективным подтверждением недобросовестности миџ, уполномоченных на заключение Аоговоров о приватизации, является уголовная статистика. Сравнительно недавно обнародованы факты о том, что в половине регионов к различным срокам мишения свободы были приговорены члены руководства аАминистраций, территориальных комитетов по управлению имуществом и фондов имущества. Их вина состояла в предоставлении незаконных преференций агентам транснационацьных корпораций [6]. Именно в конце 1990-х - начале 2000-х годов коррупция в Казахстане превратилась в суррогат национацьной идеи, вокруг которой объединицись многие граждане независимо от социального происхождения, этнической принадлежности, вероисповедания, пола, возраста, политических симпатий. Аажке успешные казахстанские банкиры, встретившиеся в 2013 г. в неформальной обстановке, опреАелили существующий экономический строй как «коррупционный капитализм» [7, р. 4] . В его рамках сложно обеспечить поступательный рост валового внутреннего продукта и создать предпосылки Аля стадиального прорыва.

Маркером неблагополучия в отношении коррупџии и одновременно одной из ее причин явцяется степень «открытости» / «закрытости» органов государственного управления. В июне 2012 г. агентство «Рейтинг.kz» провело исследование четырех факторов транспарентности республиканских министерств и веАомств с ранжированием от одного до четырех бамлов. Бымо опрошено 55 экспертов, представляющих сферу бизнеса, неправительственные организации и аналитическое сообщество. Средние значения таковы: 1) наличие обратной связи с населением / целевой аудиторией - 2,84 бамла; 2) взаимодействие с институтами гражданского общества - 2,65; 3) открытость дмя СМИ - 2,39; 4) проведение обшественных слушаний по законопроектам и разцичным инициативам - 2,69. Согласно выбранной методике максимальный уровень «открытости» составцял 18,5 бамла. Все правительственные учреждения уложились в диапазон от 2,58 (Национальное космическое агентство - последнее, 40-е место) до 8,32 (Министерство культуры и информации - 1-е место). Организаторы пришии к единодушному мнению, что это «чрезвычайно низкий показатель [8] .

Транспарентность не возникает спонтанно, ее обеспечивают институты, формирующие гражданское общество и плюралистическую среду. В Казахстане таковые есть, но, видимо, не в полной мере реализуют свое предназначение. Кстати, ни один из двадцати депутатов Мажкилиса и Сената, которым были направлены анкеты агентства «Рейтинг.kz», их не заполнил, хотя именно парламентарии по роду занятий регуцярно взаимодействуют с центральными исполнительными органами, и их оџенки представцяли бы значительную ценность Аля составмения объективной картины. 
Партии, парламент, суд, «третий сектор» должны быть в авангарде демократических преобразований. Если это требование не выполняется, то происходит «опережкюющая институщионализация», когда важнейшие современные общественные институты используются не Аля мегитимации перспективных моделей соџиального взаимодействия, а только как учреждения, символизирующие модернизащию [9, с. 16] .

Известно, что вероятность коррупционных сделок во многом зависит от размера вознаграждения за добросовестную работу. Оно должно быть таким, чтобы сумма «делового предможения» не могла побудить чиновника совершить Аолжностное преступление. Среди правителей Азии раньше Аругих это понял сингапурский премьер-министр $\Lambda$ Куан Ю, пребывавший на своем посту с 1955 по 1986 г. и заслуженно получивший титулы «творџа экономического чуда» и «победителя коррупции». Несмотря на скромные возможности бывшей островной колонии Великобритании, чья территория не превышает двух мегаполисов, сравнимых с Алматой, зарплаты чиновникам и судьям там были установлены в пределах 20-25 тыс. домл. в месяџ - больше, чем в США [10]

Специалисты единодушны во мнении, что политика увеличения заработной платы сотрудникам государственного аппарата в странах с относительно низкими доходами населения оправдана. Скромные официальные окмады государственных служащих, напротив, создают весомые стимулы дця коррупции, которая начинает рассматриваться как приемлемый персональный способ выживания и преодоления экономических трудностей. Если в частном секторе зарплата выше, то самые трудолюбивые и способные уйдут туда, а на их место устроятся некомпетентные и недобросовестные кадры, предрасположенные к противоправным деяниям. Сегодня каждый десятый молодой человек в Казахстане сознательно ориентирован на низкооплачиваемые позиции в государственных структурах, поскольку убежден, что основой «навар» принесут коррупџионные действия [3, с. 119]. При этом этическая сторона вопроса игнорируется. Специалисты подчеркивают, однако, что улучшения материального положения недостаточно. Оно должно сочетаться с оптимизацией управления и установлением эффективного контроля за действиями персонала и расходованием ресурсов [11, с. 76-78].

Расчеты показывают, что в Республике Казахстан среднемесячная номинальная заработная плата руководителей организаций государственного управления и обороны составляет $14,6 \%$, руководителей организаџий образования $-9 \%$, зАравоохранения $-13 \%$ от соответствуюшего показате я в нефте- и газодобывающих отраслях. В наиболее выгодном положении находятся государственные служашие Астаны. 3Аесь наивысший уровень номинальной заработной платы этой категории занятых по стране (191 763 тенге) и максимальный положительный разрыв по сравнению со средней заработной платой в регионе (он составляет 43476 тенге), что обусловлено расположением в городе центральных органов государственного управления и власти. Естественно, Аля Аанной группы чиновников издержки коррупции, выражающиеся в опасности навсегда потерять престижную должность, 
как и стимулы к честному труду, достаточно высоки. На противоположном полюсе, в зоне серьезных коррупционных рисков находятся Атырауская и Мангистауская области - центры нефте- и газодобычи (Авукратная отрицательная разница).

Страны, входящие в первую десятку IPC ТI, отказались от карьерной системы оплаты труда на государственной службе, когда единые тарифные оклады устанавливает законодатель, и внеАрили позиџионный подход, позволяющий самому ведомству в рамках выделенного бюджета назначать индивидуальные ставки. В Швеции, например, сегодня 90\% чиновников получают такое «персонифицированное» жалованье. Позиционная система дает возможность платить больше за цучшую работу, а не за Аолжность, и вознаграждать квацифицированных специалистов на том уровне, который в Аанный момент принят в бизнесе [12, с. 191-192].

Мощный барьер против взяточничества и расхищения государственных средств - страх ожидаемого наказания. Ангажированные бюрократы научимись его диверсифиџировать путем распределения криминальных ролей межАу начальниками и подчиненными, а также «централизацией» рынка своих услуг через выработку негласных тарифов на принятие нужных решений [11, c. 81-82]. Самоуправство и имююзия безнаказанности, келейность и отсутствие гласности, моральный ремятивизм и негативная мотивация - все это создает питательную среАУ Аля экономических преступлений в государственном секторе.

Казахстан - самая большая центральноазиатская страна с уникальным геополитическим положением, самобытной культурой и огромным ресурсным потенциалом. На его территории пересекаются интересы множества государств, каждое из которых пытается обеспечить себе режим наибольшего благоприятствования. Применяемые ими технологии вцияния не могут не учитывать «могику повсеАневности», имеющую родовое сходство с коррупционными практиками. Но это именно сходство, а не тождество. Парадокс в том, что шансы на успех у инициатора подкупа (как и у соответствующего уполномоченного органа по противодействию коррупции) повысятся, если отказаться от идеологемы «всепроникающей тотальной продажности» и принять во внимание аффирмативное (эмпирически подтвержденное) знание о реальных и свойственных искцючительно данному обществу представлениях, Аействиях и отношениях межАу АюАьми, связанных с возможностями уиучшения их материального положения ици статуса. Имеют значение этнокультурная и конфессиональная специфика, семейный укцаА, сетевые контакты, корпоративная культура, профессиональная этика, мировоззрение и иные социальные оболочки индивида, которые определяют его убежкеения в вопросе о том, «что такое хорошо и что такое плохо». Преимущество, конечно, за теми, кому и «стены помогают».

Казахстанџы полагают, что их своеобразный менталитет и широкое распространение родственных связей явцяются репликаторами теневых практик. В этом уверено более трети населения страны $(37,9 \%)$ [3, с. 57]. Вместе с 
тем в непотизме и фаворитизме в угоду «своим» усматривается не нарушение официальных правиц и инструкций, призванных регламентировать публичную сферу, а гуманное, «человеческое», миџо бюрократа, Аорожащего расположением близких и всегда готового им помочь связями и влиянием. Предполагается, что человек решается обратиться к высокопоставценному брату, свату или Аругу, поскольку считает Аачу взятки «постороннему» Аолжностному мицу крайней мерой, к которой стоит прибегать мишь в критических обстоятельствах, что объективно сужкает коррупџионное поле. Если и приходится нести какие-либо накцадные расходы, то они относительно невелики и преАставцяют собой выражение искренней признательности, а не соучастие в уголовном преступлении. Результат целенаправленных действий оказывается одним и тем же (например, получение нужного разрешения или заказа), однако интерпретация путей его достижения не снижает самооценки и авторитета взаимодействующих сторон, которые Аемонстрируют Аруг Аругу соџиальную компетентность, верность Аолгу и зАоровый прагматизм. Отказ в подАержке или неблагодарность приведут к «потере мица», а чрезмерная опека «чужака» обязательно вызовет подозрения во взяточничестве [13, с. 70 - 72] .

Аля последовательного проведения взвешенной антикоррупционной помитики важно учитывать, что конструирование «сетей солидарности» имеет иную природу, чем построение коррупционной сети. Если первое воспринимается окружающими (и инсайдерами, и аутсайдерами), как норма жизни, то второе - тяжкий соџиальный недуг, который требует оперативного мечения. Критерий их разцичия - наличие / отсутствие Алительных мичных отношений взаимопомощи, где соображения материальной выгоды мибо не играют существенной роли, мибо, наоборот, поставлены во главу угла.

С правовой точки зрения членство в солидарной группе - это незначительный административный проступок, а вхождение в коррупџионный консорциум, особенно функционирующий на постоянной основе, есть преступление против национацьной безопасности. Как следствие, степень ответственности варьируется от Аисџиплинарного взыскания Ао Алительных сроков мишения свободы с конфискаџией имущества. Суровые меры наказания прожженным коррупџионерам приветствуются населением Казахстана. Периодически выдвигаются предложения применять к ним смертную казнь. Тех же, кто способствует разоблачению нечистых на руку чиновников, общественное мнение рассматривает как честных мюдей и Ааже героев [3, с. 61, 114].

Проанализированные факторы коррупции: гипертрофия государственных функций в экономике, затрудненный Аоступ к информации о деятельности исполнительной ветви вцасти, слабость «третьего» сектора, неАостаточный размер оплаты труда государственных служащих, консервативные сощиальные установки - серьезно осложняют криминогенную обстановку. ОАнако они преходящи и при наличии политической воли подАаются коррекции. Это позволяет надеяться, что почва Аля коррупџионных деяний в Республике Казахстан будет неукмонно сокращаться. 


\section{Библиографический список}

1. О разрешениях и уведомлениях: Закон Республики Казахстан от 16 мая 2014 г. № 202-V. URL: http://online.zakon.kz/Document/?doc id=31548200\#pos=1;-307\&sel link=1005053738.

2. Как начать свой бизнес в Дании. URL: http://sauninadk.blogspot.ru/p/blog-page_14.html

3. ТОО «ПРЭКО-Консалтинг». Аналитический отчет по социологическому исследованию «Определение индекса восприятия коррупции в Республике Казахстан». Астана, 2015.

4. Курганников Д. Великолепная сотня из тысячи. URL: http://www.raexpert.kz/about/smi/ $\operatorname{art51/}$

5. GFI: Казахстан стал лидером по незаконному выводу капитала среди стран ЦА. URL: http://etoday.kz/finances/12642-gfi-kazahstan-stal-liderom-po-nezakonnomu-vyvodu-kapitala-sredi-stran-ca.html

6. Борьба с коррупцией в государственных органах Республики Казахстан: учебное пособие / под ред. Е.О. Алауханова. URL: http://www.allpravo.ru/library/doc101p0/instrum6770/ item6782.html

7. Satpaev D. Corruption in Kazakhstan and the Quality of Governance // IDE discussion paper. 2014. № 475. Р. 1-29.

8. Составлен рейтинг транспарентности министерств и ведомств Казахстана. URL: http:// online.zakon.kz/Document/?doc_id=31214601\#pos=1;-285

9. Мыслящая Россия. Картография современных интеллектуальных направлений / под ред. В. Куренного. М., 2006.

10. Уход Ли Куан Ю: кого потеряла мировая экономика. URL: http://forbes.kz/life/hero/ uhod_li_kuan_yu_kogo_poteryala_mirovaya_ekonomika/.

11. Альжсанова Ф.Г. Актуальные проблемы противодействия коррупции в системе государственной службы Республики Казахстан // Коррупция: основные тенденции противодействия. Новосибирск, 2015. С. 59-86.

12. Полникова А.А. Причины возникновения коррупционных преступлений среди сотрудников правоохранительных органов Казахстана: основные недостатки и способы их устранения // Юридическая наука: история и современность. 2013. № 12. С. 190-195.

13. Сиссенер T.K. Феномен коррупции в антропологической перспективе. URL: http://www. cisr.ru/files/publ/Windmills/3_Corruption_Book.pdf. 